\title{
Elisabeth Seys, Ces femmes qui écrivent. De Madame de Sévigné à Annie Ernaux
}

\section{Francesca Forcolin}

\section{Q OpenEdition}

1 Journals

\section{Edizione digitale}

URL: http://journals.openedition.org/studifrancesi/2325

DOI: 10.4000/studifrancesi.2325

ISSN: 2421-5856

\section{Editore}

Rosenberg \& Sellier

\section{Edizione cartacea}

Data di pubblicazione: 1 aprile 2014

Paginazione: 200-201

ISSN: 0039-2944

\section{Notizia bibliografica digitale}

Francesca Forcolin, «Elisabeth Seys, Ces femmes qui écrivent. De Madame de Sévigné à Annie Ernaux », Studi Francesi [Online], 172 (LVIII | I) | 2014, online dal 01 avril 2014, consultato il 18 septembre 2020. URL : http://journals.openedition.org/studifrancesi/2325; DOI : https://doi.org/10.4000/studifrancesi. 2325

Questo documento è stato generato automaticamente il 18 settembre 2020.

\section{(c)}

Studi Francesi è distribuita con Licenza Creative Commons Attribuzione - Non commerciale - Non opere derivate 4.0 Internazionale. 


\title{
Elisabeth Seys, Ces femmes qui écrivent. De Madame de Sévigné à Annie Ernaux
}

\author{
Francesca Forcolin
}

\section{NOTIZIA}

ELISABETH SEYs, Ces femmes qui écrivent. De Madame de Sévigné à Annie Ernaux, Paris, Ellipses, 2012, pp. 443.

1 Elisabeth SEYs traccia, nel suo volume, un'evoluzione, un complesso e faticoso percorso fatto di interrogativi, esitazioni, conquiste, contrasti. È l'evoluzione della condizione femminile, l'analisi del ruolo delle donne all'interno della famiglia e della società nel corso dei secoli; la lenta, lentissima conquista dei diritti, l'opposizione tra le aspirazioni e il modello patriarcale imposto; è una presa di consapevolezza che si fa man mano più acuta, più incisiva, e che parte dall'appropriazione di quello strumento del potere che è il linguaggio. È la vita delle donne vista dalle donne, donne non più descritte dagli uomini che ne hanno dato, fino alla fine del XIV secolo, un'immagine falsificata: donne nella loro realtà, autrici di se stesse che si svelano in testi in prima persona, opere dove il "je" trionfa. Colei che scrive, che si scrive, diventa l'eco di un momento, di un tempo, l'immagine di un contesto, «le témoignage d'aspirations et de regrets, de souffrances et de bonheurs».

2 Sono dodici i capitoli di cui è composto il volume (da leggersi come un'antologia), uno per ogni scrittrice: dodici le autrici francesi selezionate da SEYS, dal Medioevo a oggi. Ogni capitolo segue la medesima struttura: la prima pagina riassume l'analisi proposta. Successivamente viene inquadrato il periodo storico in cui vive la scrittrice e la relativa condizione femminile; segue un paragrafo sulla sua biografia, l'analisi approfondita di un testo - quel testo, ci dice l'A., che funge da "chambre de résonance" dell'epoca: opera 
in prima persona che dipinge la scrittrice e la donna nella sua totalità -, infine l'eredità lasciata dall'autrice, considerando letture e riletture della sua produzione.

Dopo un'esauriente introduzione (pp. 5-12), il primo capitolo verte su Christine de Pizan (1364-1430). L'idéal politique au féminin? (pp. 13-43), autrice, sotto il regno di Carlo V, de La cité des dames, immagine allegorica di una città perfetta, costruita e presieduta da tre dee, città utopica in risposta al discorso maschile. Dal Medioevo al Rinascimento: passano cento anni e l'A. si sofferma su Marguerite de Navarre (1492-1549). La femme en perspective (pp. 45-79), donna coltissima e dalla rigida educazione, autrice de l' Heptaméron, raccolta di novelle sulla scia di Boccaccio: si tratta di una sorta di autoritratto dell'autrice, testimonianza del suo ruolo attivo nella politica dell'epoca. Un secolo divide la regina di Navarra e Madame de Sévigné (1626-1696). L'autoportrait aux miroirs (pp. 81-113). La condizione femminile evolve, soprattutto nell'ambito culturale, nonostante la differenza sessuale sia ancora rigida. La fitta corrispondenza tra Madame de Sevigné e la figlia è all'origine delle Lettres, opera che, nella descrizione della vita quotidiana mescolando dialogo e monologo, immerge il lettore nei costumi dell'epoca, preannunciando il genere autobiografico. Passano ancora cento anni e ci troviamo tra $\mathrm{i}$ fermenti che anticipano la Rivoluzione: siamo nella Francia di Luigi XVI con Madame Roland (1754-1793). L'invention d'une écriture citoyenne (pp. 115-147), donna e scrittrice politicamente attiva, che nei suoi Mémoires particuliers ha saputo mescolare materiale autobiografico e storico, disegnando così un lucido ritratto della condizione femminile del xvIII secolo. Lo scarto temporale si accorcia, e si riduce sempre più avvicinandosi ai giorni nostri: nella Francia di Napoleone troviamo Madame de Staël (1766-1817). L'autobiographie masquée (pp. 149-181), autrice, tra il resto, di Corinne ou l'Italie, autobiografia non detta, mascherata dalla finzione, in cui Madame de Staël, celandosi dietro il suo personaggio, si racconta in quanto artista. Il sesto capitolo è dedicato a Flora Tristan (1803-1844). Une enquêtrice à la recherche d'elle-même (pp. 183-213), scrittrice socialmente engagée negli anni della fine dell'impero napoleonico, dell'industrializzazione, del pauperismo. Il viaggio in Perù che Flora Tristan descrive in Pérégrinations d'une paria è essenzialmente iniziatico, un manifesto in prima persona sui diritti delle donne, quello del divorzio in primis. Contemporanea di Tristan è George Sand (1804-1876), presa in esame nel capitolo Autobiographie d'un nom (pp. 215-246), la quale attraverso l'opera Histoire de ma vie risulta essere la prima scrittrice a pubblicare un testo apertamente autobiografico, testo che si pone come la genesi di un'identità che si allontana dai ruoli e dai doveri entro i quali la società racchiude le categorie sessuali. Segue Colette (1873-1954). Vivre et écrire au féminin (pp. 247-277), con l'analisi dell'opera Sido: qui, spiega l'A., accediamo «à une forme pure d'autobiographie, où l'auteur se dit, et à une forme féminine d'autobiographie», in cui l'autrice si racconta attraverso il personaggio mitico della figura materna. Molto lontana dalle autrici analizzate finora è Simone de Beauvoir (1908-1986), Naissance d'une pensée (pp. 279-310): la scelta di Elisabeth Seys cade sui Cahiers de jeunesse, 1926-1930, testimonianza dello strappo tra l'io dell'autrice e quello, invece, reclamato dalla società, la non obbedienza alle regole, il rifiuto delle imposizioni. Quasi contemporanea a de Beauvoir è Marguerite Duras (1914-1996). La féminité comme élan (pp. 311-341). Ne L'Amant, il legame tra la narratrice $\mathrm{e}$ il cinese è considerato dall'A. come un rapporto iniziatico che permette la nascita di un questionnement identitaire, nonché una riflessione sul ruolo delle donne nella società coloniale. Segue, nel capitolo XI, Marguerite Yourcenar (1903-1987). Repenser l'interrogation sur la femme (pp. 343-375), in particolare l'analisi del testo Le Labyrinthe du monde, opera in prima persona costituita da tre tomi, in cui la donna è "pensée autrement": non da 
un punto di vista femminile, bensì umano, non in opposizione alla figura maschile, ma donna in quanto tale, poiché è nella contrapposizione che la differenza tra i sessi perde di significato. Chiude il volume l'analisi su un'autrice contemporanea, Annie Ernaux (1940). L'infigurable visage féminin (pp. 377-408), e sulla sua scrittura autosociobiografica (in particolare Les Années), storia personale che riflette una realtà comune, un movimento dal je al nous che traccia l'evoluzione e la condizione femminile. Seguono alcune pagine conclusive (pp. 409-412), la Chronologie - La condition féminine en France du Moyen âge à nos jours (pp. 413-416) e la bibliografia. 